\title{
Intuição, sentidos e caminhos possíveis para um método cartográfico no campo do design visual
}

Intuition, senses and possible way through the cartographic method in visual design

\author{
Marcelo Gonçalves Ribeiro, Fernanda Rodrigues Alvares
}

cartografia, tecnologia, sinestesia, design visual

Este artigo tem como objetivo analisar e discutir a cartografia, um dos métodos contemporâneos de pesquisa qualitativa. O método cartográfico tem orientado a exploração de novos territórios no campo do design no contexto da era da tecnologia digital. Neste trabalho, relatamos o desenvolvimento da cartografia aplicada a um projeto específico: oferece uma forma flexível e tangível de acompanhar e refletir sobre a pesquisa no campo do design.

cartography, technology, synesthesia, visual design

This article aims to analyze and discuss cartography, one of contemporary qualitative research methods. The cartography method has guided the exploration of new territories in the design field in the context of the digital technology era. In this paper, we report on the development of the cartography applied for a specific project: offering a flexible and tangible way of accompanying and reflecting on design's research.

\section{Introdução}

Para estudar a leitura e produção de imagem, considerando o atual contexto da tecnologia digital, Gunther Kress (2003) nota a necessidade em entender que há uma longa história da representação a partir do pensamento ocidental e que contribuiu para separação entre materialidade e os sentidos, ou seja, mente e corpo, e consequente separação de cognição, afeto e emoção. O autor compreende ser impossível manter a cognição separável do afeto, mas percebe essa dicotomia na linguagem, cuja organização divide essas duas noções e, por este motivo questiona:

É necessário não apenas repensar, mas re-lexicalizar a linguagem. Uma vez que isso ocorra - e não foi, até agora - podemos começar a olhar em um sentido mais amplo para as inter-relações dos modos e disposições sociais humanas. Qual é o efeito sobre as disposições do uso dominante do visual em vez do oral, do visual escrito em vez do oral? Não apenas em termos de efeitos na memória, mas em termos de disposições corporais mais profundas? Como seriam as disposições humanas se dependêssemos muito mais dos modos de ação? Ou do visual? (Kress, 2003, p. 146, tradução nossa)

Conforme o autor nos diz, essas perguntas possuem respostas complexas e múltiplas, pois a linguagem determina a maneira de compreender o mundo. Por meio da criação de artefatos

Anais do $10^{\circ} \mathrm{CIDI}$ e $10^{\circ} \mathrm{CONGIC}$

Kelli C.A.S. Smythe, Rafael de Castro Andrade (orgs.) Sociedade Brasileira de Design da Informação - SBDI Curitiba | Brasil | 2021
Proceedings of the $10^{\text {th }} \mathrm{CIDI}$ and $10^{\text {th }} \mathrm{CONGIC}$

Kelli C.A.S. Smythe, Rafael de Castro Andrade (orgs.)

Sociedade Brasileira de Design da Informação - SBDI Curitiba | Brazil | 2021 
imagéticos, o design visual está integrado potencialmente com aspectos do signo, compreendidos, apresentados e usados tradicionalmente na sociedade por meio da comunicação visual. O design da informação, ocupado com a criação da representação de conhecimentos complexos, também envolve aspectos da informação que são culturais.

Aspectos culturais são determinantes, pois toda comunicação é, em certa medida, culturalmente condicionada. De uma forma mais específica, a educação ou difusão informacional trata do impacto dos meios visuais de comunicação nas atitudes, emoções e conhecimentos humanos, mas também limitam e padronizam nossas compreensões do mundo ao redor. Gunther Kress (2003) também nota isso ao considerar prováveis efeitos sociais e culturais mais amplos no futuro, tendo em vista que os efeitos do movimento para a tela como o meio de comunicação dominante produzirão mudanças de longo alcance e que não se restringem à esfera da comunicação, mas envolvem relações de poder.

O autor nota a necessidade de pensarmos na relação multimodal,

Nos conjuntos multimodais, da escrita e da imagem, ou da escrita, da fala, da imagem, da música e assim por diante, as possibilidades de complementar as mensagens com significado se multiplicam e incorporam as demandas e os potenciais de imaginação de todos os modos envolvidos. A isso devemos acrescentar o processo nunca ausente de sinestesia, a transdução interior, na interpretação, entre os modos - do falado ao visual, do som à cor, da imagem ao cheiro, e assim por diante. A nova teoria do significado e da semiose - e, derivando delas, da aprendizagem - que acredito ser necessária terá de se preocupar com tais questões. (Kress, 2003, p. 146, tradução nossa)

A partir dessas observações, é possível formular algumas indagações iniciais: será que a procura pela comunicação informacional não destinaria ao designer a tarefa de estabilizar diferentes informações? E, com isso, direcionar conceitos estabelecendo "categorias sob medida" às ideias já existentes? Ao trabalhar a comunicação visual informacional, não estaríamos direcionando as informações aos segmentos já cristalizados? É possível notar outras necessidades que escapam dessas categorizações previstas ao pensarmos no processo de sinestesia?

O presente artigo traz uma reflexão sobre parte da pesquisa de mestrado que está em desenvolvimento no Programa de Pós-Graduação em Design pela Universidade Federal do Rio de Janeiro. O trabalho prático envolve processo de experimentação que pretende observar a associação dos sentidos, ressignificação e memória de signos do nosso cotidiano. Durante a pesquisa, foi realizada a construção e organização de artefatos, tendo como apoio inicial vários materiais, temperos e frutas tropicais encontrados em uma feira livre ${ }^{1}$ do Rio de Janeiro. Alguns artefatos foram organizados e outros recriados de maneira lúdica, buscando evidenciar dois pontos principais: a relação de alguns sujeitos com esses objetos e sua expectativa em relação ao aroma e memória visual; e, ao mesmo tempo, uma proposta de ruptura da expectativa

\footnotetext{
${ }^{1}$ Foi realizada escolha por "feira livre", e um local específico do bairro serviu de espaço para a experiência da dissertação. No Rio de Janeiro, a feira livre é uma antiga tradição de comercialização no espaço urbano e, em alguns casos, são realizadas vendas diretas entre produtor e consumidor de produtos como itens alimentares (frutas e legumes frescos, especiarias, ervas, entre outros) e não alimentares (flores, alguns utensílios de cozinha, entre outros). As instalações são provisórias e montadas nas áreas abertas e públicas da cidade.
} 
inicial, a partir de embaralhamento intencional de aromas e cores, desassociando-as das suas respectivas representações.

No livro Information Design, Robert Jacobson (2000) admite a importância de um design específico, na medida em que alguns estudos de métodos apresentados por pesquisadores como Brenda Dervin, o Sense-Making, "geralmente são específicos ao contexto", podendo não produzir o mesmo efeito em outra abordagem. (Jacobson, 2000, p. 5, tradução nossa)

Do mesmo modo, Ellen Lupton e Andrea Lipps (2018) defendem a ideia que o funcionamento e o desenvolvimento profissional e humano precisam envolver o design sensorial, na medida em que enaltece a experiência corporal e sensações de caráter diverso por meio de texto e informações. (Lupton \& Lipps, 2018, p. 163)

Neste sentido, experimentos dentro e fora do campo do design são importantes para o entendimento dessa complexidade. A era atual de avanços no desenvolvimento de uma ampla gama de tecnologias, softwares e aplicativos, tornaram possível usar, implantar e aplicar as Realidades Aumentada (AR), Mista (MR) e Virtual (VR), por exemplo, em vários níveis de uso e para diferentes objetivos e experimentos. Desse debate também resulta um pensamento que questiona as fronteiras entre natural e artificial, real e virtual, material e imaterial, entre outros. Assim, nota-se a importância em investigar para, além dos signos culturais, sensações e interações procurando evitar a divisão notada por Gunther Kress (2003).

A título de exemplo, em 1957, Morton Heilig desenvolveu e patenteou o Simulador Sensorama, uma máquina que oferecia experiência e sensações em uma espécie de "ciclismo" virtual. O Sensorama, aperfeiçoado em 1962, apresentava não apenas o som estéreo e o display estereoscópico, mas também uma cadeira vibratória, um emissor de aromas e fragrâncias. Durante a simulação do passeio virtual, o espectador ouvia sons das ruas da cidade, sentia o vento e as vibrações do assento e envolvia inclusive aromas que sugeriam o caminho percorrido. (Greengard, 2019)

Samuel Greengard (2019) nota que o impacto dessas experiências virtuais não está restrito aos pixels, sons e sensações físicas que uma realidade artificialmente induzida consegue produzir. Essas tecnologias remodelam o pensamento individual e as atitudes sociais em grande escala. (Greengard, 2019)

Diante dessas abordagens, aproximando o pesquisador do observador envolvido com a experiência, nosso intuito neste texto é realizar uma reflexão sobre as observações de Robert Jacobson (2000), procurando pensar, por outras vias, algumas respostas à indagação realizada por ele no fim do século passado. A partir dessas questões, podemos adicionar outras, considerando as transformações provocadas pelas tecnologias no mundo atual e que dizem respeito às relações de sinestesia, conforme nos apresentou Gunther Kress (2003). Indivíduos (designer, observadores, pesquisadores, entre outros) certamente estão imersos no seu próprio contexto cultural, contudo, a capacidade do leitor de imagens de interpretar essas mensagens, envolve importantes "saberes" para o processamento (codificação e de decodificação) de uma mensagem visual. 
"Saberes mobilizados" é a noção usada por Roland Barthes (1990) em A Retórica da Imagem. A ideia de Barthes é que há correlação entre a situação que mobiliza "saberes" de um indivíduo e o significado que este atribui ou decodifica: ou seja, uma imagem percebida tem relação com diferentes "saberes" que passam também por aspectos cotidianos e corporais e não apenas visuais. Conforme diz Barthes, para imaginar o frescor dos ingredientes apresentados na imagem publicitária dos produtos "Panzani", antes, de algum modo na nossa vida foi necessário ter contato com um legume "fresco" e saber da diferença para um produto enlatado, pois nos diz o autor: "basta já ter feito compras algum dia" (Barthes, 1990, p. 29).

Muitos desses "saberes" são evocados por uma força cognitiva e cultural, visando uma análise formal e muitas vezes utilizada no campo do design como apoio racional para a pesquisa científica. Entretanto, essas relações não possuem simplicidade: há um entrelaçamento de subjetividades atravessando esse indivíduo e, no caso específico do design visual, devemos compreender que muitos significados não derivam exclusivamente do consciente ou da percepção visual.

\section{Intuição a partir de Bergson e Deleuze: caminhos possíveis para uma cartografia no Design}

A filosofia de Henri Bergson foi estudada por Gilles Deleuze (1999) visando a buscar uma alternativa para pensamentos dicotômicos, entre eles a noção positivista, que prevaleciam na filosofia, ao menos, a partir do século XIX. Para Deleuze, Bergson acreditava na possibilidade de conhecer os fatos, mas um obstáculo estava cristalizado no conhecimento: as ferramentas da linguagem destinam-se a atender as necessidades da vida prática e, com este objetivo, há uma redução da complexidade do mundo, simplificando-o sob o pretexto da necessidade de ação sobre a matéria. (Deleuze, 1999)

No intuito de entrar em contato com essa complexidade da vida real, Bergson sugere existir a intuição, uma maneira de "simpatia" com a qual nos movemos para o objeto e nos identificamos com o que é único nesta relação. Segundo Gilles Deleuze: "A intuição é o método do bergsonismo". (Deleuze, 1999, p. 7)

Formuladas por Gilles Deleuze (1999), a partir de Bergson, apresentaremos três atos que determinam regras do método da intuição: o primeiro deles é o ato problemático que realiza uma crítica aos problemas colocados incorretamente por meio das dicotomias. O segundo é o ato diferenciado, ou seja, dividindo e cruzando informações procurando as verdadeiras diferenças dissociadas das dicotomias. Deleuze (1999) nos diz: a intuição "reencontra as diferenças de natureza sob as diferenças de grau e comunica à inteligência os critérios que permitem distinguir os verdadeiros problemas e os falsos" (Deleuze, 1999, p. 13-14). O terceiro é o ato duração, tendo em vista o pensamento no tempo real, ou seja, a duração não pode ser artificialmente dividida em momentos regulares individuais, como ocorre em um relógio, por se tratar de uma convenção. A duração como experiência deve reconhecer a existência de outras 
durações: o tempo vivido é uma continuidade, um passado que está presente e que anuncia o porvir ao mesmo tempo. (Deleuze, 1999, p. 23)

Assim, o método intuitivo de Bergson esforça-se para articular as coisas de acordo com sua natureza, afastando-se de conceitos que impedem potências da investigação. Para isso, Bergson busca pensar a memória como um dos elementos que conectam momentos e transferem o passado para o presente. Sendo este um dos níveis que definem a filosofia de Bergson, a memória é pensada por Deleuze por meio da imagem de um "cone" em que as qualidades do passado e do presente são distribuídas onde "há todo o nosso passado, mas em graus diferentes" e "o presente é somente o grau mais contraído do passado", como na ponta de um "cone". (Deleuze, 1999, p. 136)

\section{Feira Livre: signos, caminhos e sentidos}

Assim, esse modo dinâmico e complexo que podemos pensar sobre o design da informação, considerando definições signos a-significantes e significantes que são (re)estruturados constantemente, (re)agrupados e (re)modelados nas diferentes mensagens no campo do design, nos remetem a uma imagem curiosa: a feira livre.

Neste momento, abordaremos a importância do trabalho cartográfico realizado no campo do design, a partir de uma pesquisa em desenvolvimento e que uma das etapas foi realizada na feira livre na cidade do Rio de Janeiro e outra etapa em ambiente de laboratório de Química na Universidade Federal do Rio de Janeiro. Para que ganhassem forma, foi necessário um estudo feito em parceria com o Instituto de Química da UFRJ, sob auxílio da professora Claudia Moraes de Rezende - que desenvolve atividades de pesquisa e desenvolvimento nas áreas de Química do Aroma - e do pesquisador Eduardo Costa Pinto da Cruz, buscando formas de trazer os aromas da feira livre.

Considerando essa difícil tarefa de documentação das sensações que envolve, além de pessoas em diferentes momentos da investigação, entre outros aspectos, a discussão sobre a cultura tradicional de pesquisa no campo do design, Busca-se nesta segunda parte uma abordagem diferente da investigação dos fenômenos dados no momento de exploração da feira livre, pensando pela perspectiva do design Por que pensar a partir da Feira Livre? Uma Feira Livre possui organizações improvisadas e temporárias em cada espaço, mas esse local é demarcado pela via e na definição de distribuição dos vendedores. Ao longo do caminho, nossa caminhada pela via é remodelada a partir de fragmentos das mensagens e códigos específicos dos feirantes: falas, cores, aromas, texturas e burburinhos estão entrecortados, diluídos ou enfatizados por nossas memórias.

Brian Massumi (2016) apresenta esta complexidade no texto "A arte do corpo relacional: do espelho-tátil ao corpo virtual". Massumi acrescenta a este problema, identificando que as imagens não evocam apenas o sentido visual, pois a separação dos sentidos de forma totalitária não é atingida. Experiências que podemos considerar mono-sensoriais são, na verdade, uma apresentação intermodal de um sentido dominante (Massumi, 2016, p.10). 
Massumi (2016, p.10) declara que a visão envolve experiências potenciais de outros sentidos, e que não seria possível atingir a definição de uma visão em particular sem a presença deles. Sendo assim, o design está envolto de percepções sensoriais que vão além da visão; são complementos, que atuando simultaneamente, resultam no todo.

Então, levantamos como questão: como esse conjunto de sensações podem coexistir de maneira ordenada em forma de pensamento? Como o designer, sendo o organizador da informação, se faz presente nessa equação a título do individual e coletivo?

O livro Pistas do método da cartografia, Eduardo Passos, Virgínia Kastrup e Liliana da Escóssia (2009), nos apresenta um panorama do processo que busca resistir à metodologia que se impõe como palavra de ordem, ou seja, quando a pesquisa é definida como um caminho predeterminado por metas estabelecidas no início.

Os autores destacam o trabalho de Tânia Mara Galli Fonseca (2003) no livro Cartografia e devires: A construção do presente, quando a autora nota problemas cruciais para o campo da pesquisa. Em outro texto, desenvolvendo alguns pontos sobre a cartografia, Tânia Mara Galli Fonseca e Fernanda Amador (2009, p. 6), observam que o cartógrafo pode se ver imerso pelas "forças da inteligência", deixando-as sobrepostas às dimensões não fixas e não ordenáveis do campo da pesquisa. Segundo ambas e, também de acordo com Virgínia Kastrup em em curso ministrado, são oito pistas do cartógrafo. Porém, seguindo a apresentação das autoras e sua relação com a teoria de Henri Bergson apresentada antes, vamos nos ater a três delas: sua ocupação com o traçado de um campo problemático, a dissolução do ponto de vista do observador e a atenção específica ao presente (Amador \& Fonseca, 2009, p.6).

Essas três pistas traçam um paralelo tanto com a cartografia quanto com o design, usando, como exemplo, a experiência da feira livre. É sobre pensar no trabalho cognitivo do fluxo das informações e da absorção das mesmas em um ambiente repleto de sensorialidade e estímulos, com códigos específicos. E também sobre a relação da experiência do próprio pesquisador nesse campo da pesquisa do design.

O cartógrafo, que pode ser o designer como pesquisador, produz material de pesquisa no momento em que problematiza o campo. E é nesse determinado ponto em que se extingue o ponto de vista do observador. De acordo com Amador e Fonseca (2009):

Trata-se de ideias radicalmente novas tanto em relação ao campo quanto ao pesquisador, em um processo em que, por uma zona de contato, ambos deixam, de certo modo, de ser o que são. Tal dissolução marca a força que faz sair da dicotomia o par sujeito-objeto, instaurando um processo de dupla captura em que pesquisador e campo se fazem em um movimento implicado-explicado. (Amador \& Fonseca, 2009, p.6)

Essa relação está dentro do primeiro ponto levantado como "o traçado de um campo problemático". Indo ao encontro da feira livre, o que vemos à primeira vista no nosso "campo problemático" é um mar complexo de elementos que, a priori, se misturam como uma massa não organizada. O caos em meio a uma organização é o que torna o ambiente estimulante/intrigante. De acordo com Massumi (2016, p.12): 
Primitivamente, nossas experiências espaciais constituem um caos, do qual não temos uma capacidade imediata de desenredá-las. Objetos de distintos órgãos dos sentidos, experimentados ao mesmo tempo, em primeira instância, aparentam estar dentro, encostados ou muito distantes uns dos outros, dispostos de maneira espacialmente contínua ou descontínua, ou em qualquer definição dessas palavras. (Massumi, 2016, p.12)

Segundo Massumi (2016, p.12), o potencial da percepção espacial é envelopado em um continuum multissensorial, onde as sensações oriundas dos sentidos irão decompor em uma experiência espacial, que, em um primeiro momento, não tem a aparência de que estejam separadas. E podemos observar esse território quando começamos a entrar na feira, revelando as partes da massa.

Em um primeiro momento, barulho, cores, aromas, texturas. Sem muitas definições, sem frases, sem identificação. Aos poucos, a trama vai se desenrolando e surgindo dimensões. Para Massumi (2016. p.11), sempre há um número de dimensões de sensações; a experiência pode ser recomposta a partir da variação da intensidade dos seus elementos. Sempre que experimentada novamente, de uma nova forma, atinge novos picos, apresenta-se em novas determinações, que, em princípio, podem ter infinitas variedades.

De acordo com o pensamento de Amador e Fonseca (2009, p.6):

Há um lance de dados pelo olhar do pesquisador que, em um primeiro momento, pode parecer uma expressão demasiada de individualismo e subjetivismo. Contudo, pelos elementos fornecidos pelo pensamento bergsoniano, constitui-se justamente em outra coisa, qual seja: o remetimento para um campo propriamente coletivo. Referimo-nos a um coletivo não tomado a partir de critérios quantitativos e personalizados - como conjunto numericamente estabelecido -, mas enquanto zona de multiplicidades e de impessoalidade.

É como "não ser", mas "fazer parte". No caso da feira livre, sendo um espaço temporário mas altamente proprietário, os envolvidos momentaneamente estão fazendo parte de um coletivo: frequentadores e feirantes, coexistindo e transformando o espaço a todo momento. No caso do designer, assume-se uma parcela dentro do projeto, colocando-se à experiência. Segundo Denise Portinari e Bruno Barros (2011, p.92), o design participativo propõe a substituição do projetar "para" alguém, por projetar "com" alguém.

E essa relação do projetar está relacionada à experiência e a intuição. Estar presente ativamente no campo problemático, emerge a seguinte questão, levantada por Amador e Fonseca (2009, p.3):

Trata-se de uma invenção que somente se torna viável pelo encontro fecundo entre pesquisador e campo pesquisa, pelo qual o material a pesquisar passa a ser produzido e não coletado, uma vez que emerge de um ponto de contato que implica um deslocamento do lugar de pesquisador como aquele que vê seu campo de pesquisa de um determinado modo e lugar em que ele se vê compelido a pensar e a ver diferentemente, no momento mesmo em que o que é visto e pensado se oferece ao seu olhar. (Amador \& Fonseca, 2009, p.3)

E isso nos leva à segunda pista do cartógrafo: a dissolução do ponto de vista do observador. Para Amador e Fonseca (2009, p.6), o traçar de um campo problemático enquanto cartógrafo significa problematizar as formas cognitivas do próprio pesquisador em sua relação 
com o campo de pesquisa. O mesmo ocorre quando o designer está inserido no seu campo de pesquisa (no caso, a feira livre) de modo participativo. Traçar esse campo problemático é importante para que se rompa a forma cognitiva do pesquisador, distanciando-se do próprio repertório, abrindo caminho para novas problematizações.

Segundo Amador e Fonseca (2009, p. 6):

Tal pista põe em evidência a importância de que, na pesquisa, o pesquisador venha a se conduzir na direção de resoluções inventivas, que o forçam a traçar novos problemas, em uma inconformidade incessante que lhe permite não ceder às seduções das respostas apaziguadoras ligadas ao plano da recognição. Em lugar disso, produz vitalidade às forças que dão existência às coisas, produzindo material de pesquisa no momento mesmo em que problematiza o campo. (Amador \& Fonseca, 2009, p.6)

É nesse ponto que ocorre a dissolução do ponto de vista do observador, e que Bergson anuncia tal dissolução quando fala que a clareza que surge da intuição é, de alguma forma, obscura por se referir a uma ideia radicalmente nova, tanto em relação ao campo quanto em relação ao próprio pesquisador. A dissolução acontece quando a oposição entre sujeito e objeto é deixada de lado, dando espaço a um processo de dupla captura, em um movimento implicado-explicado. (Amador \& Fonseca, 2009, p. 6).

Para Amador e Fonseca (2009, p.6), é criando centros de estabilidade momentânea no caos, ao que denominamos de zona de duração, que o cartógrafo empreende sua tarefa. $\mathrm{E}$ isso implica diretamente a última das três pistas as quais foram exploradas neste artigo: a atenção específica ao presente. De fato, a grande questão que envolve essa última pista é como centrar a atenção a algo que está continuamente em movimento, se modificando? No caso específico da feira, como reter a atenção em um presente onde a todo tempo passantes entram em seu caminho, feirantes cantam suas mercadorias, uma torrente de signos e forças externas estão intervindo?

Para Amador e Fonseca (2009, p.7), é preciso focalizar a atenção e reconhecer que o foco não está na estaticidade, mas que se mantenha em constante movimento pela memória, esforçando-se para que elementos preexistentes não gerem influência e definam esse momento.

$\mathrm{Na}$ experiência da feira livre, essa atenção específica ao presente se reflete em entender particularidades, peculiaridades. É nesse ponto em que surgem, para o designer que está participando dessa experiência, problematizando, dissolvendo seu ponto de vista e retendo sua atenção, que, conforme Amador e Fonseca (2009, p.7), possibilita-se não exatamente ver objetos-processos, mas visioná-los, inventá-los, fabulá-los pelo plano dos perceptos e dos afectos, acionando potências impessoais e inobjetais.

\section{Conclusão}

A partir da intuição descrita no método cartográfico, o trabalho prático envolveu o processo de experimentação em uma feira livre no Rio de Janeiro. À vista disso, surgiu a principal problemática, que seria o cerne da pesquisa: o design para além da visualidade, onde os sentidos são parte ativa da experiência, explorando memórias do cotidiano e ressignificações. 
A pesquisa em desenvolvimento, da qual resulta parte deste texto, busca compreender quais aspectos da comunicação visual envolvem múltiplos sentidos. Diante de resultados provisórios obtidos por meio de objetos que desorientam a expectativa das pessoas, pelo olfato, por exemplo, surgem novas inquietações que ampliarão a pesquisa.

Atualmente, um dos principais pontos das Realidades Aumentada, Virtual e Mista é a busca por uma experiência totalmente integrada. Como diz Samuel Greengard (2019), enganar o olho e a mente humana e "fazê-los acreditar que o ambiente artificial é igual a um ambiente físico requer sensores, sistemas e dispositivos totalmente integrados". (Greengard, 2019. P. 39)

O desenvolvimento das pesquisas com detectores de movimento, sensores de pele, entre outros tipos são fundamentais também para o campo do Design Visual e, por isso, é necessário compreender a abrangência dos sentidos humanos. (Greengard, 2019. P. 39)

Concordamos com a observação de Greengard que o impacto dessas experiências virtuais, realidade produzida artificialmente, transformam e remodelam o pensamento individual e as atitudes sociais em grande escala. Por esse motivo, notamos a importância de pesquisas que envolvam aspectos sensoriais que valorizem a intuição, afetos e memória. (Greengard, 2019. P. 154)

Outras análises e resultados apresentaremos em futuro trabalho, contudo, podemos antecipar, como resumo, que após a experiência da feira livre, começaram a ser geradas alternativas para que esses elementos tão característicos, como aromas, materiais, temperos, se transformassem - e (res)significassem - em artefatos.

A busca por evidenciar a relação do sujeito com o objeto se desdobrou, a princípio, em questões sobre aroma e memória visual. A partir de uma conversa no próprio laboratório de Química, surgiram questionamentos sobre a expectativa do sujeito com relação ao objeto. É dado como certo para as pessoas que uma laranja, com forma de laranja, cor laranja, terá cheiro de laranja. Mas e se não tiver? Surgiu então uma proposta de ruptura com expectativas, embaralhando intencionalmente aromas, cores e formas, e rompendo as suas respectivas representações. Foi uma maneira encontrada para dar vida ao caos da feira livre, em objetos aparentemente simples.

Chegada ao final dessa etapa, começaram a ser realizados testes práticos, principalmente com relação aos aromas. Nesse momento, junto à professora Claudia Moraes de Rezende e ao Eduardo Costa Pinto da Cruz, foi proposto por eles um método que atenderia à demanda, chamado Encapsulamento de Aromas com alginato de sódio e capsul, onde o aroma permanece confinado em microesferas por meses e, para liberar este aroma, basta comprimir a microesfera entre os dedos. Para o projeto em desenvolvimento, foram escolhidos alguns aromas distintos, dentro da categoria Frutal. (CRUZ, 2009)

Como conclusão provisória, por tratar-se de uma pesquisa em andamento, sublinha-se que um dos pontos relevantes para as próximas ações, é instigar questões acerca do conceito de transdução, no sentido de expansão com meios e no desafio de projetar, nesses objetos: que seriam parte da feira livre, com seus signos, seus aromas, seu caos, parte da experiência que conecta cada um à sua própria memória; que trouxesse a indagação e a surpresa, ao se 
deparar com cores, formas e aromas embaralhados; que fizesse com que cada experiência fosse única, com afectos e perceptos próprias daquele sujeito, assim como foram experienciadas na feira livre por aquele que os projetou.

\section{Referências}

Amador, F; \& Fonseca, T. M. G. (2009). Da intuição como método filosófico à cartografia como método de pesquisa - considerações sobre o exercício cognitivo do cartógrafo. Arquivos Brasileiros de Psicologia, vol. 61, núm. 1, pp. 30-37 Universidade Federal do Rio de Janeiro, Rio de Janeiro, Brasil

Barthes, R. (1990). A Retórica da Imagem. In: O óbvio e o obtuso. Rio de. Janeiro,Nova Fronteira, pp. 27-43

Cruz, E. C. P. da (2009). Microencapsulamento de Aromatizantes. [Dissertação de Mestrado não publicada]. Orientadora: Claudia Moraes de Rezende. Ciência de Alimentos. Universidade Federal do Rio de Janeiro, Brasil

Deleuze, G. (1999). Bergsonismo. Trad.: Luiz Orlandi. São Paulo: Ed. 34

Fonseca, T. G., \& Kirst, P. G. (2003). Cartografia e devires: a construção do presente. Porto Alegre: Editora da UFRGS

Greengard, S. (2019). Virtual reality. Cambridge, MA: MIT Press

Jacobson, R. (2000). Information Design. Cambridge: The Mit Press

Kastrup, V. (2007). O funcionamento da atenção no trabalho do cartógrafo. Psicologia e Sociedade, Porto Alegre, v. 19, n. 1, jan./abr.

Kress, G. (2003) Literacy in the new media age. New York: Routledge

Lupton, E., \& Lipps, A. (2018). The Senses: Design Beyond Vision. New York: Copper Hewitt, Smithsonian Design Museum, Princeton Architectural Press.

Massumi, B. (2016). A arte do corpo relacional: do espelho-tátil ao corpo virtual. Trad.: André Fogliano. Revista Galáxia. n 31, jan./abr. São Paulo, Online. 2016, pp.5-21. Disponível em: https://revistas. pucsp.br/index.php/galaxia/article/view/26462

Passos, E., Kastrup, V., \& Escóssia, L. (Orgs.) (2009). Pistas do método da cartografia: pesquisa-intervenção e produção de subjetividade. Porto Alegre: Sulina.

Portinari, D., \& Barros, B. (2011). O kan e a espada: por uma retomada da noção de intuição na metodologia projetual. In: L.A. Coelho (org.) Design Método. Rio de Janeiro: Novas Ideias, pp. 94-102

\section{Sobre os autores}

Marcelo Gonçalves Ribeiro, Dr., UFRJ, Brasil <marceloribeiro@eba.ufrj.br>

Fernanda Rodrigues Alvares, Mestranda, UFRJ, Brasil <nandarodrigues.go@gmail.com> 